\title{
Intermittent oxygen flux from the interior into the bottom boundary of lakes as observed by eddy correlation
}

\section{Andreas Brand}

Eawag, Swiss Federal Institute of Aquatic Science and Technology, Surface Waters Research and Management, CH-6047 Kastanienbaum, Switzerland; Institute of Biogeochemistry and Pollutant Dynamics, ETH Zurich, CH-8092 Zurich, Switzerland

\section{Daniel F. McGinnis}

Eawag, Swiss Federal Institute of Aquatic Science and Technology, Surface Waters Research and Management, CH-6047 Kastanienbaum, Switzerland

\section{Bernhard Wehrli and Alfred Wüest}

Eawag, Swiss Federal Institute of Aquatic Science and Technology, Surface Waters Research and Management, CH-6047 Kastanienbaum, Switzerland; Institute of Biogeochemistry and Pollutant Dynamics, ETH Zurich, CH-8092 Zurich, Switzerland

\begin{abstract}
Turbulent oxygen transport from the overlying stratified water column into the bottom boundary layer (BBL) on the slope of a medium sized lake was investigated using the eddy correlation (EC) technique. The seiche induced oscillatory flow of the BBL, with a period of $\sim 1 \mathrm{~d}$, was identified as the mechanism driving turbulent oxygen transport. Sporadic short term EC vertical oxygen fluxes exceeded the sedimentary oxygen uptake of $13 \pm$ $2 \mathrm{mmol} \mathrm{m}{ }^{2} \mathrm{~d}^{1}$ calculated from sediment oxygen profiles by more than a factor of three. The average EC flux over half of a seiching period was $9.2 \mathrm{mmol} \mathrm{m}{ }^{2} \mathrm{~d}^{1}$ similar in range to the flux into the sediment; however, these two fluxes do not have to coincide spatially and temporally. The EC oxygen flux was only significant when the deep basin scale currents exceeded a velocity of $2 \mathrm{~cm} \mathrm{~s}{ }^{1}$ and the corresponding bottom shear was sufficient to produce active turbulence. Below this threshold, decaying turbulence resulted in oxygen fluxes lower than $3.5 \mathrm{mmol} \mathrm{m} \mathrm{2} \mathrm{d}^{1}$, with an even lower average flux of $0.8 \mathrm{mmol} \mathrm{m}^{2} \mathrm{~d}^{1}$ observed during reversals of the seiching. At low velocities, the weak turbulence is insufficient to transport dissolved oxygen through the stratified top of the BBL (stability $N^{2} \approx 2.4 \times 10^{4} \mathrm{~s}^{2}$ ), even though turbulence was found in the inertial subrange and periodical bottom convective mixing was still present. The EC technique provided valuable data on the temporal variability of oxygen transport related to the BBL hydrodynamics and flux pathways.
\end{abstract}

The eddy correlation (EC) technique is a well-established method to determine atmospheric fluxes of water vapor, carbon dioxide, nitrous oxide, and others between water and air or soil and air (e.g., Famulari et al. 2004; Lee et al. 2004). This method is based on the simultaneous measurements of the fluctuations of turbulent velocity $\left(u_{j}^{\prime}\right)$ and concentration $\left(c^{\prime}\right)$ : The product of both variations results in the momentary turbulent fluxes of a substance horizontally and vertically $\left(u^{\prime} c^{\prime}\right.$ and $\left.w^{\prime} c^{\prime}\right)$, respectively. The net turbulent flux is obtained by averaging this fluctuation product over a given time span. Berg et al. (2003) were the first to determine sedimentary oxygen uptake in aquatic systems with an EC approach in fluvial and coastal marine sites. The resulting oxygen flux estimates agreed well with those determined with traditional techniques, like flux

\section{Acknowledgments}

We thank Christian Dinkel, Michael Schurter, and Daniela Richter for support in the field; John Little for improving the English of the manuscript; and two anonymous reviewers and Josef D. Ackerman for valuable remarks. D.F.M. was supported by the Swiss National Science Foundation (grants 200020 103827.1 and 200020 111763.1) and A.B. by Eawag. chambers and the evaluation of oxygen profiles in the sediment. Kuwae et al. (2006) recorded time series between 12 and $40 \mathrm{~min}$ over a tidal mudflat during daytime and nighttime and showed that the EC method could also be used to investigate photosynthesis. McGinnis et al. (2008) recorded the diurnal cycle of photosynthesis and respiration in a run-of-the-river hydropower reservoir in Switzerland. These studies revealed the excellent potential of the EC technique for quantifying solute dynamics under turbulent conditions.

Here we use the EC technique to examine oxygen flux in a turbulent system that demonstrates strong intermittency. Specifically, we examined the bottom boundary layer (BBL) of lakes where there is strong variability due to sporadic energy input. Lake Alpnach, a prealpine lake with regular, nonsteady basin-scale deep currents, was chosen as the study site because convective winds from the surrounding mountains force the lake-internal seiching that generates regular BBL dynamics (Gloor et al. 2000). Two different seiche modes were observed in Lake Alpnach: the first horizontal, first vertical seiche mode with a typical period of 8 to $12 \mathrm{~h}$ and the first horizontal second vertical seiche mode with a period of approximately $1 \mathrm{~d}$ (Münnich et al. 1992). 
BBLs influence the exchange of momentum, heat, solutes, and particles with bottom sediments and the turbulent dissipation of energy from currents and waves (Wüest and Lorke 2003). In addition, BBL dynamics affect bottom regions that provide habitat for benthic microorganisms and invertebrates and are sites of biogeochemical activity in lakes (Maerki et al. 2006) and oceans (Boudreau and Jørgensen 2001). It is, therefore, important to explore the relation between BBL dynamics and the exchange of solutes between bottom waters and the sediment in more detail.

From a microscale perspective, it is already known that BBL turbulence near the bottom has been shown to influence sediment oxygen uptake (Lorke et al. 2003) since the thickness of the diffusive boundary layer (DBL) correlates with shear and physically limits oxygen transport at the sediment water interface (Jørgensen and Marais 1990). Here we explore the link between turbulent dynamics and solute exchange at larger scales within the BBL (typically up to several meters above the sediment surface). We also investigate the required conditions for applying the EC technique under nonsteady conditions, caused by seiches typical of the near bottom environment.

\section{Methods}

Study site Measurements were conducted at 27-m water depth over the sloping sediment on the southeast side of Lake Alpnach (46 $\left.57^{\prime} 51^{\prime \prime} \mathrm{N}, 8^{\circ} 18^{\prime} 13^{\prime \prime} \mathrm{E}\right)$ starting on 14 September 2005 at 16:00 $\mathrm{h}$ and ending 15 September 2005 at 04:00 h. The lake is a medium-sized mesotrophic subbasin of Lake Lucerne in Central Switzerland. It has an elliptical shape of approximately 5 by $1.5 \mathrm{~km}$, a surface area of $4.2 \mathrm{~km}^{2}$, and a maximum depth of $34 \mathrm{~m}$. Lake Alpnach is separated by a 3-m-deep sill from the rest of Lake Lucerne. For most of the time, inflowing water merges into the surface layer, since it consists of warm epilimnetic water from an upstream lake. However, the measurements were conducted 3 weeks after a flood event discharging warm and highly turbid water into the hypolimnion of Lake Alpnach.

Experimental setup The experimental arrangement consisted of three devices. A densely spaced vertical thermistor array was used for measuring continuous temperature profiles $4 \mathrm{~m}$ above the bottom sediments in order to observe the macroscopic development of the BBL at the slope. Sixteen TR-1000 thermistors (RBR Oceanographic Instrumentation) were fixed on the tripod with $0.25-\mathrm{m}$ spacing. Temperature was logged every $3 \mathrm{~s}$. Prior to the measurements, the sensors were simultaneously calibrated in a 7025 Benchtop Calibration Bath (Hart Scientific), which reduced the sensor-to-sensor differences to $\sim 1 \times 10{ }^{\circ} \mathrm{C}$ (Lorke et al. 2005).

Sedimentary oxygen consumption rates were calculated from oxygen microprofiles recorded in the top few millimeters of the sediment using the lander system LISA (lander for ion selective analysis) (Müller et al. 2002) equipped with two Clarke-type oxygen electrodes (Unisense). Their output signals were processed with a custom built electronics package consisting of a low-noise current- to-voltage converter with a precision instrumentation amplifier in series with a guard circuit. The signal was filtered with a $50-\mathrm{Hz}$ low-pass filter. The profiles were recorded with $0.1-\mathrm{mm}$ vertical resolution, and 300 data points were acquired at $3 \mathrm{~Hz}$ for each vertical sensor position. The electrodes were calibrated by Winkler titration, performed on samples taken at 27-m depth using a Niskin bottle. The fluxes were used for comparison with the results provided from the EC technique.

A fast-response miniature Clark-type oxygen microsensor with $10-\mu \mathrm{m}$ tip diameter (Ox-10 fast, Unisense; $<0.3 \mathrm{~s}$ for $90 \%$ signal response) was mounted next to an acoustic Doppler velocimeter (ADV, Vector, Nortek) for the EC measurements. The tip of the oxygen probe was positioned approximately $2 \mathrm{~mm}$ from the measurement volume of the ADV installed $11 \mathrm{~cm}$ above the sediment. Signal acquisition and amplification were performed at $8 \mathrm{~Hz}$ using the same electronics as in the lander system but without a lowpass filter. The setup was installed on a tripod and was deployed in the main current direction to avoid flow obstruction by the legs of the tripod.

Flux calculation Vertical velocities and oxygen concentrations were time lag corrected. The cross correlation between oxygen and vertical velocities showed the typical maxima at $\sim 2$ to $\sim 3 \mathrm{~s}$. This inferred time lag was then used for shifting the data series accordingly. Thereafter, the time series were subdivided into 15 -min subsets. Fluctuations of velocities and concentrations and their standard deviations were calculated after linear detrending.

Sediment oxygen consumption was obtained from sediment oxygen microprofiles and was calculated using the software Profile (Berg et al. 1998).

Spectral analysis Power spectral densities of vertical velocities $\left(S_{w}\right)$ and cospectral densities $\left(C o_{w c}\right)$ were calculated using the Welch (1967) method. The resulting spectra, which consisted of $N=f \times T$ (frequency $\times$ period length) data points were subdivided into $A \mathrm{Nr}=50$ intervals. The bandwidths $b_{k}$ were calculated using $b_{k}=$ $\exp (k \times \ln N / A N r)$ for each interval number $k$ (from 1 to 50). The spectral values were averaged over the resulting intervals and plotted against the central frequencies (Kaimal and Gaynor 1983).

For detailed analysis, the $C_{w c}(f)$ of the vertical velocity $(w)$ and oxygen concentration $(c)$ were subdivided into positive and negative contributions prior to band averaging. Since the sum of the two subdivided and bandaveraged cospectral densities is identical to the bandaveraged full cospectral densities, we concluded that the data separation was logically consistent.

The normalized ogives

$$
O g(f)=\frac{\int_{f}^{f_{\max }} C o_{w c}(f) d f}{\int_{f_{\min }}^{f_{\max }} C o_{w c}(f) d f}
$$

were calculated from the cospectral densities without prior band averaging. The ogive is a measure of the relative 
contribution of the frequencies above $f$ (Oncley et al. 1996) to the covariance $\overline{w^{\prime} c^{\prime}}=\int_{f_{\min }}^{f_{\max }} C o_{w c}(f) d f$ between $w$ and $c$ (Stull 1988). This integral term in the denominator also represents the average of the solute flux in the investigated time interval. If $f_{\min }$ is small enough to catch all relevant fluctuations that contribute to the flux, the ogive should reach the plateau value of 1 as $f$ decreases toward $f_{\min }$ (Desjardins et al. 1989).

\section{Results}

The following section demonstrates that the turbulent oxygen flux is highly variable in time as a consequence of the internal seiching. Therefore we start with a short description of the BBL dynamics before we present the observed turbulent fluxes and their spectral characteristics.

$B B L$ dynamics The oscillatory motions and the variable extent of the well-mixed BBL reflect the seiching of Lake Alpnach during the investigated time span (Fig. 1). The high temperatures at the bottom of the lake were the consequence of a flood event that flushed the entire basin with warm, particle-rich river water 3 weeks prior to the measurements. The stratified upper boundary of the BBL was close to the sediment at the beginning of the campaign (Fig. 1b,c). It ascended until the well-mixed part of the BBL reached a maximum height of $1.5 \mathrm{~m}$ above the bottom around $t \approx 6.5 \mathrm{~h}$ (Fig. 1b). During the same period, the vertical velocity decreased. After that period, the current changed direction at $t \approx 6.75 \mathrm{~h}$ and accelerated (Fig. 2a). Simultaneously, the well-mixed portion of the BBL decreased until it vanished almost completely at $t \approx 10 \mathrm{~h}$ (Fig. 1b). This oscillating motion of the BBL along the southwest northeast (SW NE) axis is illustrated in Fig. 1a. Obviously, we observed approximately half of the first horizontal, second vertical mode seiche period ( $\sim 1 \mathrm{~d}$ ) during the 12-h campaign (Münnich et al. 1992).

Turbulent oxygen flux The turbulent oxygen flux was extremely variable over the measurement period (Fig. 2c). Intervals with no significant flux were observed as well as periods with fluxes exceeding $40 \mathrm{mmol} \mathrm{m}{ }^{2} \mathrm{~d}^{1}$. This was three times the sediment consumption of $13 \pm$ $2 \mathrm{mmol} \mathrm{m} 2 \mathrm{~d}^{1}$ (mean \pm standard deviation) as determined from seven microsensor oxygen profiles (data not provided). Vertical turbulent oxygen transport in the range between $3.5 \mathrm{mmol} \mathrm{m}^{2} \mathrm{~d}^{1}$ and $45 \mathrm{mmol} \mathrm{m} 2 \mathrm{~d}^{1}$ was only observed when the turbulence level (indicated by the standard deviation of the vertical velocities in Fig. 2b) was sufficiently high and when the mean horizontal velocity was faster than $\sim 2 \mathrm{~cm} \mathrm{~s} 1$.

The difference in turbulence between periods with and without measurable turbulent fluxes can be readily seen by comparing recorded time series. During conditions with high turbulent flux, the vertical velocity fluctuations exceeded $2 \mathrm{~mm} \mathrm{~s} 1$ and oxygen fluctuations were larger than $1.5 \mathrm{mmol} \mathrm{m}^{3}$ (Fig. 3a), yielding a cumulative flux of $14 \mathrm{mmol} \mathrm{m} 2 \mathrm{~d}{ }^{1}$. In situations without significant turbulent flux, the vertical fluctuations rarely exceeded $1 \mathrm{~mm} \mathrm{~s} 1$
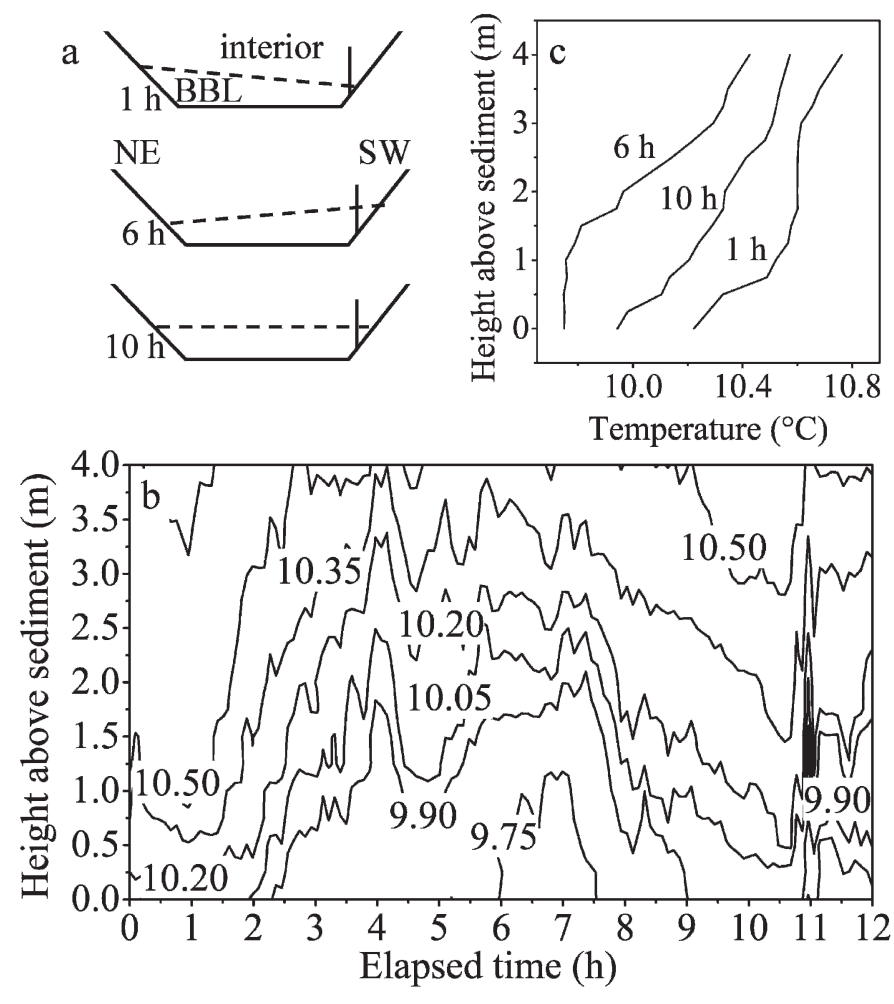

Fig. 1. Baroclinic structure of BBL in Lake Alpnach during measurements. (a) Schematic seiching motion of BBL as observed from temperature data. Vertical solid line represents thermistor chain mounted in the SW of basin. (b) Temperature $\left({ }^{\circ} \mathrm{C}\right)$ development during $12 \mathrm{~h}$ measurement from sediment surface to $4 \mathrm{~m}$ above ground. (c) $5 \mathrm{~min}$ averaged vertical temperature profiles at 1,6 , and $10 \mathrm{~h}$ of measurement. BBL has its highest extent over NE slope of Lake Alpnach during first hour of measurement. Reversal of seiche after movement toward SW with highest extent over SW margin can be observed between sixth and seventh hour. After that BBL moves back NE.

and concentration fluctuations were far below $0.05 \mathrm{mmol}$ $\mathrm{m}^{3}$ (Fig. 3b). The extremely low concentration fluctuations also indicate that the oxygen concentration gradient was close to zero. This is in agreement with the results of the temperature measurements, which indicate a well-mixed BBL at $t=6.25 \mathrm{~h}$.

We subdivided the EC time series into seven periods that differ in flux, turbulence level, and stratification (Fig. 2 and Table 1). Significant turbulent oxygen fluxes were observed in the periods II, V, and VII, where vertical velocity fluctuations around $1 \mathrm{~mm} \mathrm{~s} 1$ and temperature gradients above $0.03^{\circ} \mathrm{C} \mathrm{m}{ }^{1}$ were simultaneously present, whereas there was no measurable turbulent flux during the periods I, III, and IV when horizontal velocities were below $2 \mathrm{~cm} \mathrm{~s}$ 1. During period VI, when the average horizontal velocity just drops below $2 \mathrm{~cm} \mathrm{~s}^{1}$, the oxygen transport to the sediment simultaneously decreased with the decaying turbulence. The flux during this period was comparably low (approximately $3.5 \mathrm{mmol} \mathrm{m} \mathrm{2} \mathrm{d}{ }^{1}$ ), even though a relatively strong temperature gradient also suggests a pronounced oxygen gradient. Overall, we observed that significant fluxes only occurred when the standard devia- 


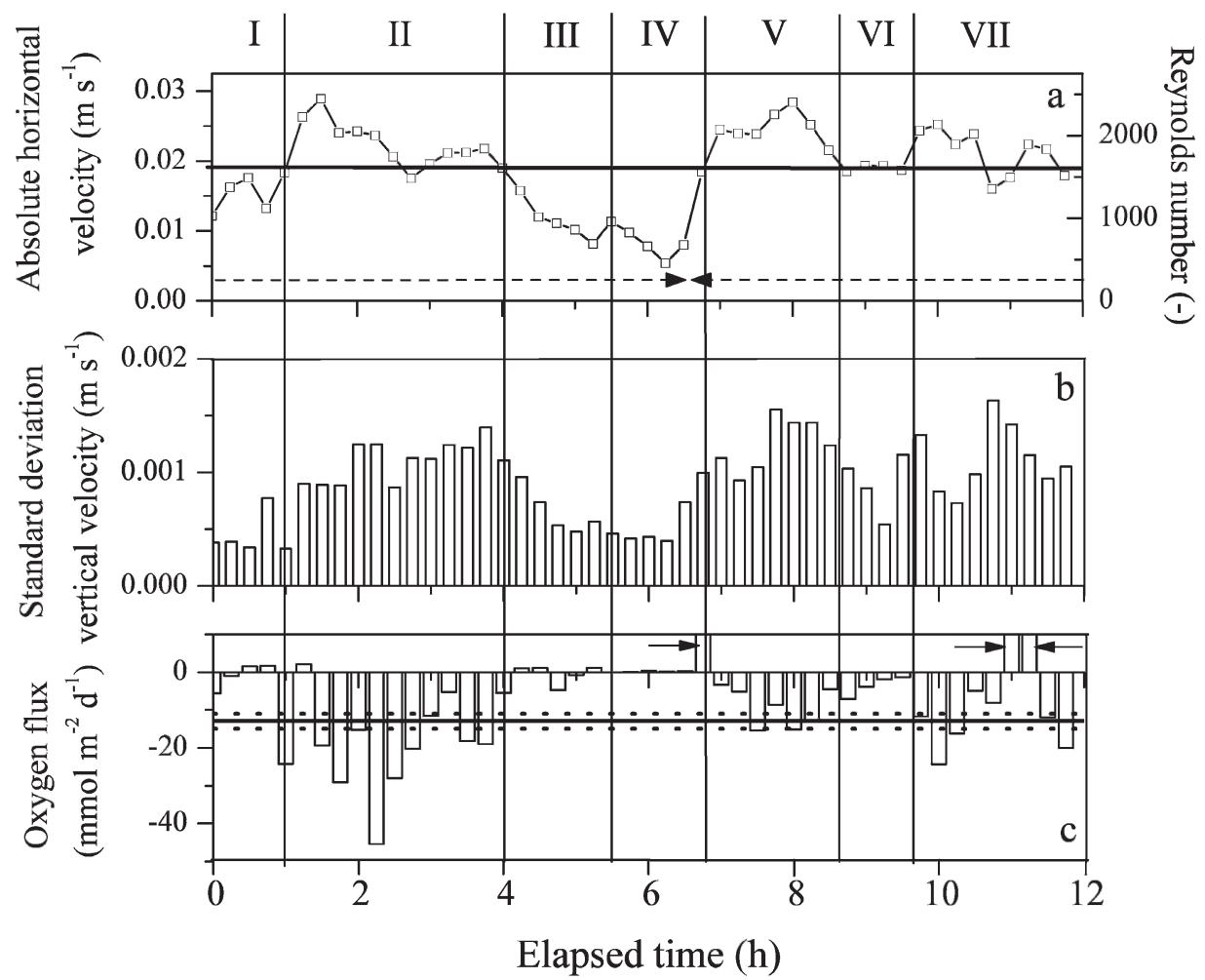

Fig. 2. Time series of $15 \mathrm{~min}$ averages of (a) absolute horizontal velocity at $0.11 \mathrm{~m}$ height above sediment. Right $y$ axis denotes corresponding Reynolds numbers calculated for a length scale equal to $0.11 \mathrm{~m}$ from sediment. Horizontal line marks threshold above which turbulent oxygen transport was observed. Arrow to right indicates flow direction to SW, arrow to left indicates flow direction to NE. (b) Standard deviation of vertical velocity and (c) vertical oxygen flux determined by EC technique (bars) in comparison with sedimentary oxygen consumption rate (solid line) and its uncertainty (dotted line). Arrows in (c) mark highly positive fluxes that were identified as artifacts of measurement during transition periods from low to highly turbulent regimes. Roman numerals I to VII mark different periods of turbulent mixing as discussed in text.

tion of the vertical velocity was at least $1 \mathrm{~mm} \mathrm{~s}{ }^{1}$, whereas no significant fluxes were detected when the standard deviation was less than $0.5 \mathrm{~mm} \mathrm{~s} 1$.

Spectral content of the turbulent fluxes In order to investigate the characteristics of the turbulent oxygen fluxes, we compared the $S_{w}$ and $C o_{w c}$ for the period $\mathrm{V}$ in which flux was observed (Fig. 4) with those of period IV without significant flux (Fig. 5). $S_{w}$ of period V (Fig. 4a) contained more energy than in period IV (Fig. 5a). In period $\mathrm{V}$, the inertial dissipation range extended between $f$ $\approx 0.02 \mathrm{~Hz}$ and $f \approx 0.15 \mathrm{~Hz}$. The ogive (Fig. $4 \mathrm{c}$ ) and $C o_{w c}$ (Fig. 4b) show that only $25 \%$ of the flux was driven by frequencies in the inertial dissipation range, whereas lower frequencies characteristic for active turbulence were responsible for $75 \%$ of the flux. The plot of the subdivided $C o_{w c}$ (Fig. 4d) shows that positive and negative contributions to the flux balanced above $f \approx 0.15 \mathrm{~Hz}$. This frequency also denotes the start of the viscous dissipation range, which is indicated by the characteristic dropoff in $S_{w}$ (Gibson and Schwarz 1963). Fluctuations toward the sediment prevailed only at lower frequencies.

The inertial subrange of $S_{w}$ in period IV (Fig. 5a) extended over frequencies between $f \approx 0.01 \mathrm{~Hz}$ and $f \approx$
$0.05 \mathrm{~Hz}$ followed by the viscous dissipation range at higher frequencies. $C o_{w c}$ showed no contributions to the flux for frequencies above $0.003 \mathrm{~Hz}$ (Fig. 5b). Positive and negative contributions balanced mainly in the considered frequency range (Fig. 5d). The ogive (Fig. 5c) does not increase as steadily as the one calculated for period V. This was typical for ogives calculated for periods with no observable turbulent fluxes.

The stepwise change from low to high vertical velocity fluctuations marked the inception of the highly turbulent regime (Fig. 6b), whereas the transition from higher down to lower turbulence levels was rather smooth (Fig. 6a). The decay of turbulence occurred when horizontal velocities fell below a threshold value around $2 \mathrm{~cm} \mathrm{~s}{ }^{1}$. This could be visualized in spectra calculated for subsequent time steps during such a period of decaying turbulence, which nicely demonstrated the gradual loss of turbulent kinetic energy (Fig. 7).

The $S_{w}$ calculated at $t=4 \mathrm{~h}$, however, still revealed a significant amount of turbulent kinetic energy. The inertial subrange was found between $f \approx 0.02 \mathrm{~Hz}$ and $f \approx 0.15 \mathrm{~Hz}$. In the spectrum at $t=4.5 \mathrm{~h}$, the inertial subrange shifted toward lower frequencies between $f \approx 0.015 \mathrm{~Hz}$ and $f \approx$ $0.07 \mathrm{~Hz}$ and a significantly lower energy level was observed 

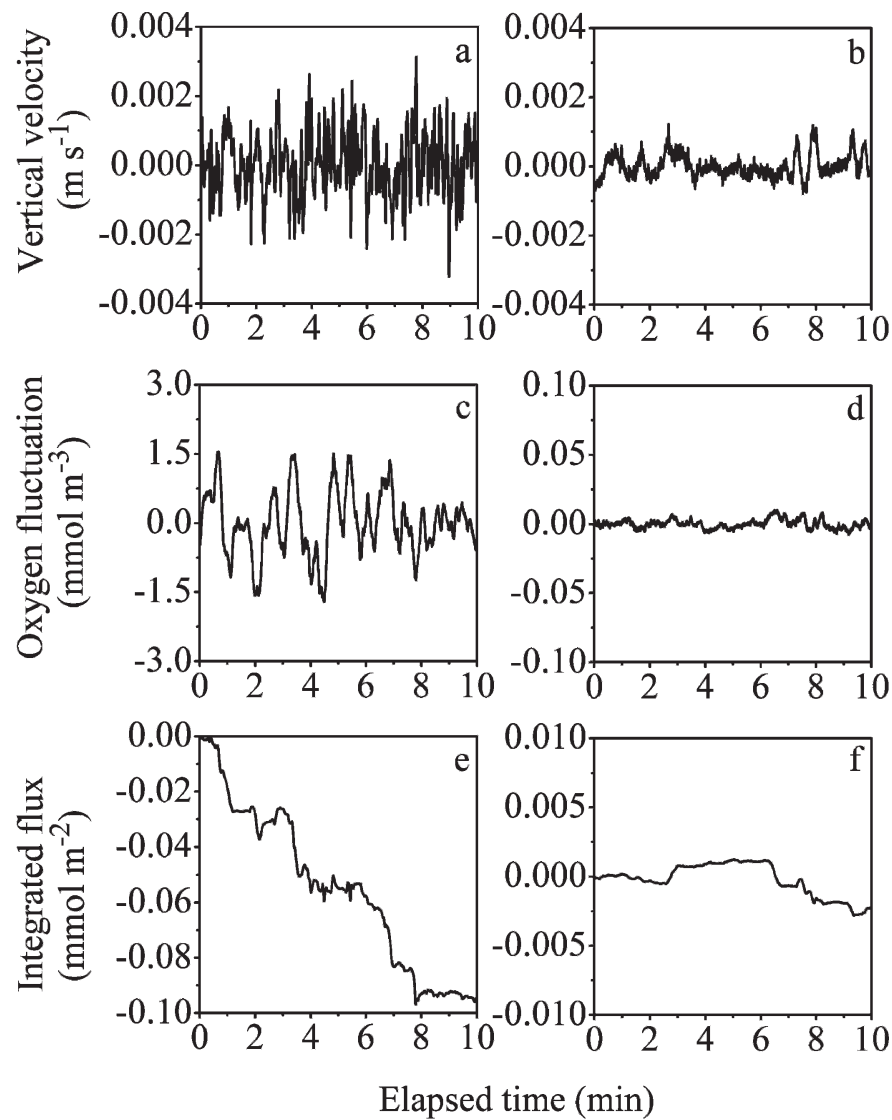

Fig. 3. (a, b) 10 min time series of vertical velocity. (c, d) Corresponding oxygen concentration fluctuations. (e, f) Integrat ed turbulent oxygen flux from 0 to $10 \mathrm{~min}$. (a, c, e) For time $t=$ 7.5 h (Fig. 2; turbulent flux). (b, d, f) For time $t=6.25$ h (Fig. 2; no significant flux).

(Fig. 7). The decay of turbulence was also reflected in the standard deviations of the vertical fluctuations from $1 \mathrm{~mm} \mathrm{~s} 1$ to $0.75 \mathrm{~mm} \mathrm{~s}^{1}$ (Fig. 1). Such examples of decaying turbulence were observed in periods III and VI.

\section{Discussion}

An oxygen uptake of $13 \pm 2 \mathrm{mmol} \mathrm{m}{ }^{2} \mathrm{~d}^{1}$ calculated from sediment profiles is typical for Lake Alpnach and lies within the range of $\sim 6$ to $\sim 13.2 \mathrm{mmol} \mathrm{m}^{2} \mathrm{~d}^{1}$ deter- mined in a previous study (Lorke et al. 2003). In contrast, EC measurements in Lake Alpnach have shown that the turbulent transport at the BBL did not always match the sediment oxygen consumption rate determined from the sediment microprofiles and was highly intermittent.

Reynolds number as an indicator for turbulent transport Turbulent oxygen transport was only observed for horizontal velocities higher than $2 \mathrm{~cm} \mathrm{~s}$. In addition, the transition from a low level of turbulence to a high level at the end of period IV occurs almost instantaneously (Fig. 6b). Both observations suggest the existence of a threshold for the production of turbulence. If no density gradients are present and the Reynolds numbers $(\mathrm{Re}=L u$ l $v$, where $L$ is the characteristic length scale that corresponds to the ADV measurement volume height above the sediment $L=z_{\text {meas }}=0.11 \mathrm{~m}$ and $v$ is the kinematic viscosity) exceeds a critical value $\mathrm{Re}_{\mathrm{c}}$, the shear must only overcome the viscous forces in order to generate turbulence. In this context, turbulent oxygen flux was only observed for Reynolds numbers above $\sim 1,700$ (Fig. 2a). This value is consistent with a critical Reynolds number of $\sim 1,500$ for the fluid flow of a stationary lower and a moving upper plate at a height $L$ (Fox et al. 2004), a situation that is similar to the flow dynamics in Lake Alpnach. Therefore, oxygen transport by eddies was only observed if turbulence was produced actively against viscous forces.

Turbulent mixing through the stratified top of the BBL Another important variable of turbulent transport through the BBL is the height $\left(h_{\text {mix }}\right)$ where shear still produces turbulence, which results in transport between the BBL and stratified lake interior. The temperature gradient of the stratified part of the BBL from the thermistor data ranged between $0.18^{\circ} \mathrm{C} \mathrm{m}{ }^{1}$ and $0.35^{\circ} \mathrm{C} \mathrm{m}{ }^{1}$ which corresponds to a stability range of $N^{2}$ between $1.6 \times 10^{4}$ and $3.1 \times$ $10{ }^{4} \mathrm{~s}^{2}$. The criterion for the production of active turbulence against a density gradient is given by Stillinger et al. (1983) and has been applied by Wüest and Gloor (1998) to BBLs in lakes:

$$
\varepsilon>C v N^{2}
$$

where $C$ is a dimensionless constant in the range between 15 and 25. The dissipation rate $\varepsilon$ is estimated for $\mathrm{BBL}$

Table 1. Time periods classified by different conditions of turbulent transport. The temperature gradient was calculated for the lowest $0.5 \mathrm{~m}$ above the sediment. The standard deviations of the vertical velocities were used as an indicator for the turbulence level.

\begin{tabular}{|c|c|c|c|c|}
\hline Section & Time $(\mathrm{h})$ & $\begin{array}{c}\text { Temperature gradient } \\
\left({ }^{\circ} \mathrm{C} \mathrm{m}{ }^{1}\right)\end{array}$ & $\begin{array}{l}\text { Vertical velocity fluctuations } \\
\qquad\left(\mathrm{mm} \mathrm{s}^{1}\right)\end{array}$ & $\begin{array}{c}\text { Oxygen flux } \\
\left(\mathrm{mmol} \mathrm{m}^{2} \mathrm{~d}^{1}\right)\end{array}$ \\
\hline I & $\begin{array}{lll}0 & 1\end{array}$ & $0.306 \pm 0.143$ & $0.5 \pm 0.2$ & $0.8 \pm 3.4$ \\
\hline II & 14 & $0.242 \pm 0.147$ & $1.0 \pm 0.3$ & $19.5 \pm 12.1$ \\
\hline IV & 5.56 .75 & $0.001 \pm 0.005$ & $0.5 \pm 0.2$ & $0.3 \pm 0.1$ \\
\hline $\mathrm{V}$ & 6.758 .5 & $0.059 \pm 0.040$ & $1.3 \pm 0.3$ & $9.3 \pm 5.2$ \\
\hline VI & 8.59 .75 & $0.058 \pm 0.021$ & $0.9 \pm 0.3^{*}$ & $3.5 \pm 2.6$ \\
\hline
\end{tabular}

\footnotetext{
${ }^{*}$ Periods during which turbulence decays steadily.
} 

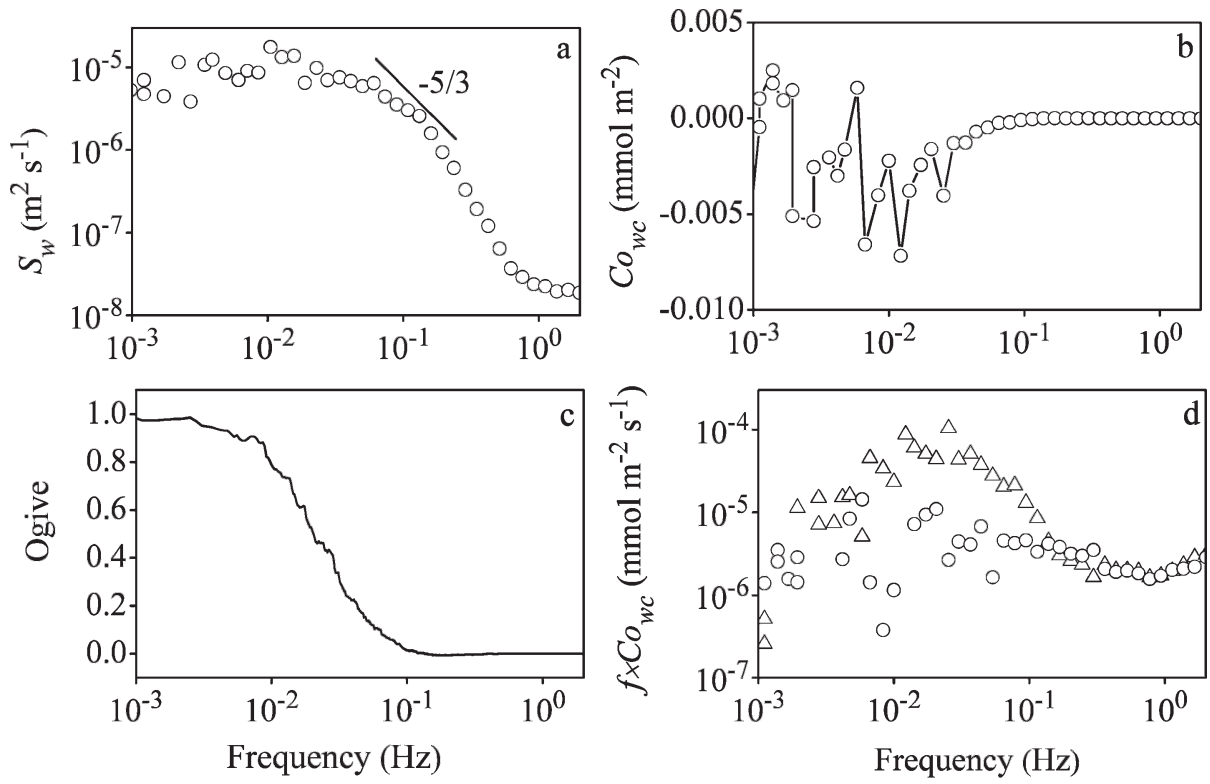

Fig. 4. Spectral analysis of a time interval from period $\mathrm{V}$ during which significant turbulent transport is observed. (a) Power spectral density $S_{w}$ of vertical velocity $w$. Black line indicates slope of inertial range. (b) Cospectral densities of $w$ and oxygen concentration $c$. (c) Ogive calculated from cospectral densities. (d) Plot of split cospectral densities (circles, contribution to flux toward sediment; triangles, contributions to flux away from sediment).

turbulence by (Caldwell and Chriss 1979)

$$
\varepsilon=\frac{u_{*}^{3}}{\kappa z}
$$

where $\kappa=0.41$ is the von Karman constant and $u_{*}$ is the shear velocity. Therefore, we find a critical shear velocity

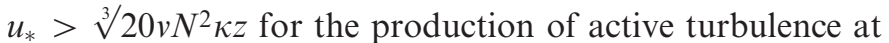
any elevation $z$ above the sediment by combining Eq. 2 and 3 and using $C=20$. Consequently, $h_{\text {mix }}$ can be calculated as

$$
h_{\text {mix }}<\frac{u_{*}^{3}}{20 v N^{2} \kappa}
$$
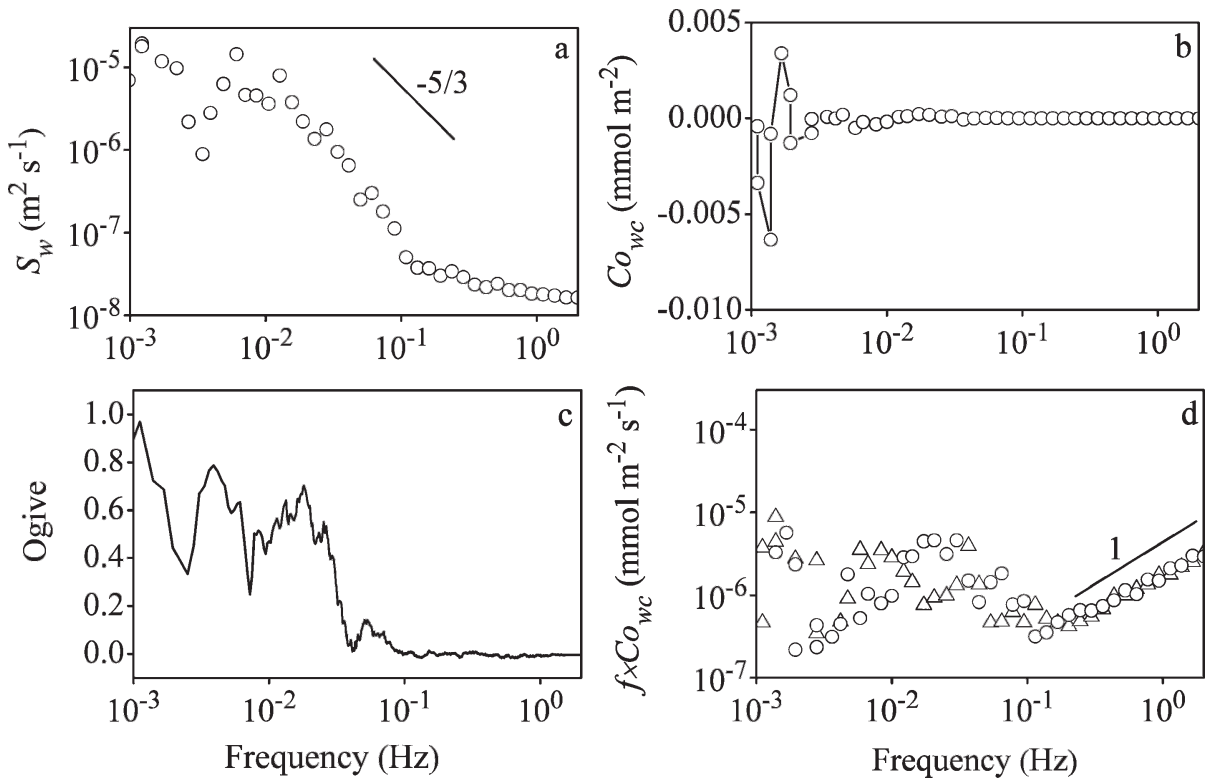

Fig. 5. Spectral analysis of a time interval from period IV during which no significant turbulent transport was observed. (a) Power spectral density $S_{w}$ of vertical velocity $w$. Black line indicates slope of inertial range. (b) Cospectral densities of $w$ and oxygen concentration $c$, (c) ogive calculated from cospectral densities, and (d) plot of split cospectral densities (circles, contribution to flux toward sediment; triangles, contributions to flux away from sediment). Straight line in (d) indicates that the signal above $0.2 \mathrm{~Hz}$ consists of noise. 


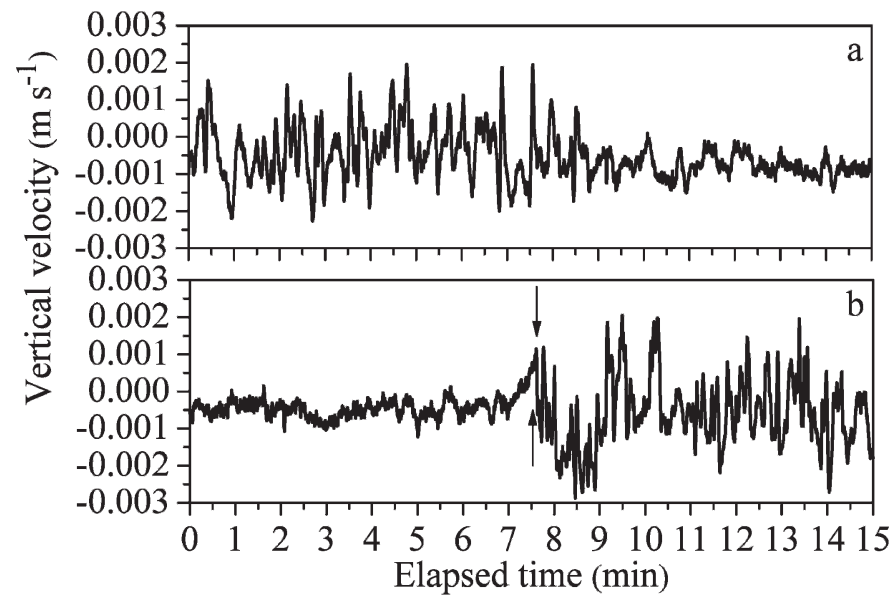

Fig. 6. Vertical velocities during transitions between periods with high and low turbulence. (a) Almost complete decay of turbulence at $t=5 \mathrm{~h}$ (Fig. 2) during 15 min data series. (b) Starting production of turbulent kinetic energy at $t=6.25 \mathrm{~h}$ (Fig. 2). Arrows indicate distinct transition from laminar to turbulent flow.

at constant shear and stratification. $u_{*}$ can be estimated from the ADV measurements at 0.11-m height from the law-of-the-wall (LOW):

$$
u_{\text {meas }}=\frac{u_{*}}{\kappa} \ln \left(\frac{z_{\text {meas }}}{z_{0}}\right)
$$

The roughness height $z_{0}$ is taken as $0.002 \mathrm{~m}$ (Brand et al. 2007). Lorke et al. (2002) showed that the LOW is valid in Lake Alpnach as long as $u>0.01 \mathrm{~m} \mathrm{~s}{ }^{1}$. Figure 8 shows the $h_{\text {mix }}$ as a function of $u$ in $0.11-\mathrm{m}$ height calculated by combining Eqs. 4 and 5. For example, $u=0.02 \mathrm{~m} \mathrm{~s} 1$ produces active turbulence up to $z=3.5 \mathrm{~m}$ above the sediment for an average stability $N^{2}=2.4 \times 104 \mathrm{~s}^{2}$ (Fig. 8).

The $h_{\text {mix }}$ also explains the long time spans of approximately $1,000 \mathrm{~s}$ that are necessary to resolve the entire spectral content of the solute fluxes, as shown in the ogives of period $V$ (Fig. 4c). The stability in this period was $1.9 \times$ $104 \mathrm{~s}^{2}$ and the average $u$ was $0.025 \mathrm{~m} \mathrm{~s}^{1}$, which corresponds to $u_{*}=0.0026 \mathrm{~m} \mathrm{~s}^{1}$ (Eqs. 3 and 5). This results in $h_{\text {mix }}=7.1 \mathrm{~m}$ (Eq. 4$)$. The timescale for the largest eddy during this period can be estimated by $h_{\text {mix }} / u_{*} \approx$ $2,700 \mathrm{~s}$. Nevertheless, the contributions of fluctuations of such long timescales are almost negligible due to their low frequency, and the ogive reaches its plateau for shorter timescales (500 to $1,000 \mathrm{~s})$.

The nature of weak turbulence during periods with no measurable flux The difference between weak and actively sheared turbulent regimes is shown in Fig. 9. Intense mixing occurs at $t=1 \mathrm{~h}$ against the strong temperature stratification $\left(N^{2} \sim 2.2 \times 10^{4} \mathrm{~s}^{2}\right)$, whereas the weak turbulence at $t=6 \mathrm{~h}$ can mix the lower part of the BBL but not the stratified top.

Decaying turbulence and shear-induced convection drive this weak turbulence during the flux-free periods. Even if the shear forces are too low to overcome the viscous forces,

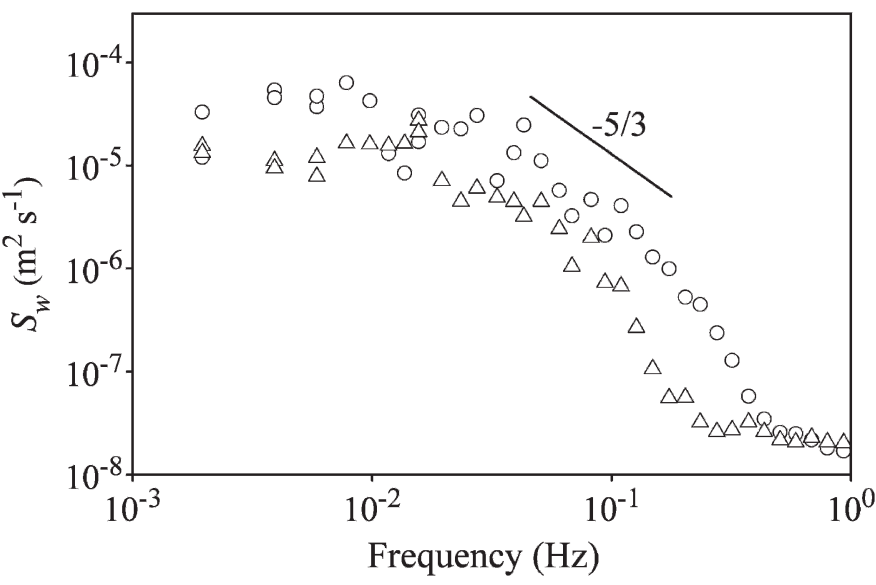

Fig. 7. Power spectral density of vertical velocity fluctua tions $S_{w}$ at $t=4.0 \mathrm{~h}$ (open circles) and $4.5 \mathrm{~h}$ (open triangles) during a period of decaying turbulence. Solid line shows slope of inertial subrange.

turbulence can be generated by convective mixing. Lorke et al. (2005) observed that seiching in Lake Alpnach can cause inverse temperature gradients that result in bottom convective mixing (BCM). Figure 10a shows that $N^{2}$ falls below zero several times during the flux-free periods III and IV. Convective mixing occurs only if the density anomaly $\Delta \rho$ caused by a temperature anomaly $\Delta T<0$ is able to overcome viscous forces and thermal diffusion. This is the case if the Rayleigh number, which is the ratio of $R a=g \Delta \rho h_{R a}^{3} / \rho K_{T} v$ where $g$ is the gravitational acceleration, $K_{T}$ is the thermal diffusivity, and $h_{R a}$ is the height of the unstable layer, exceeds a critical value of $\sim 10^{3}$ (Turner 1973). The Rayleigh number, shown in Fig. 10b for the flux-free period, indicates that intermittent convection is present, which can also cause turbulence during shear-free periods. Nevertheless, the typical height of the unstable layer was $h_{R a}=0.5 \mathrm{~m}$ above the sediment, and BCM contributed only to the internal mixing of the BBL. The weak nature of the BCM is also reflected in the low values of the Rayleigh numbers that never exceeded $3 \times 10^{6}$, in contrast to the values around $10^{8}$ observed in previous studies (Lorke et al. 2005). These low numbers can be explained by the significantly lower $h_{R a}$ in our study compared with $h_{R a} \approx 2.5 \mathrm{~m}$ observed by Lorke et al. (2005). They conducted their measurements at a depth of $32 \mathrm{~m}$, where the well-mixed part of the BBL extends farther above the sediment and BCM becomes a more important process.

Another source for weak turbulence, which can be observed during flux-free periods, is the dissipation of residual turbulence generated by previous shear. Lorke et al. (2002) showed that there is a phase lag of about $1.5 \mathrm{~h}$ between the law-of-the-wall shear and the observed dissipation in Lake Alpnach. This explains the turbulence in the inertial subrange that we observed during shear-free period III and is also reflected in the decreasing energy level in the velocity spectra at 4.0 and $4.5 \mathrm{~h}$ in Fig. 7. Nevertheless, this remaining turbulence is also too weak to mix against the density gradient. 


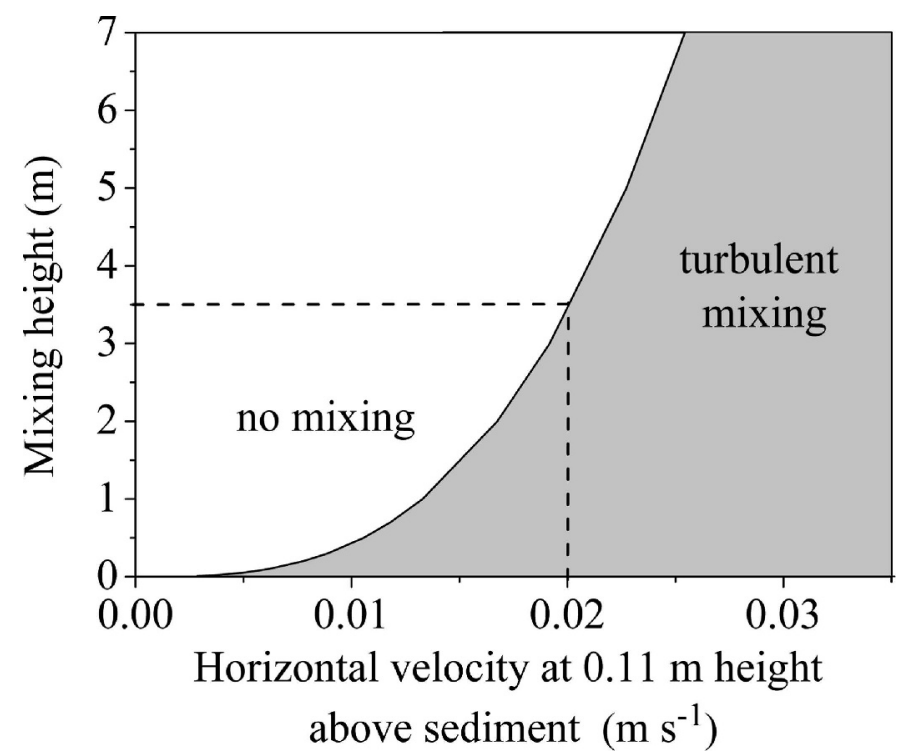

Fig. 8. Mixing height at an average stability $N^{2}=2.4 \times$ $10^{4} \mathrm{~s}^{2}$ of stratified top of BBL as a function of horizontal velocity $0.11 \mathrm{~m}$ above sediment (solid line). Turbulent BBL mixing is shown by shaded area. Dashed line denotes mixing height for critical velocity of $0.02 \mathrm{~m} \mathrm{~s}^{1}$ below which no shear induced turbulence was observed.

Conceptual model The nature of the observed turbulent oxygen transport above the sediment on the slopes of Lake Alpnach can be described by a conceptual model. The time series can be subdivided into three periods: (1) upflow, (2) deceleration and seiche flow reversal, and (3) downflow of the BBL. The conceptual steps can be visualized in Fig. 1, where the upflow occurs between $1 \mathrm{~h}$ and $6.5 \mathrm{~h}$, followed by the downflow. First, the BBL moves up the slope. The upper part of the BBL is characterized by a significant temperature gradient. The intense oxygen fluctuations during these stratified periods suggest that an oxygen gradient is also present even close to the sediment. Turbulent kinetic energy is produced by the shear from the seiching, which maintains active turbulence throughout the BBL. Oxygen-rich water is transported toward the sediment, whereas oxygen-depleted water is transported toward the interior water column. As the horizontal velocities decrease to less than $2 \mathrm{~cm} \mathrm{~s}{ }^{1}$ (seiche reversal) the flow is too weak to produce sufficient turbulent energy to transport oxygen through the stratified top of the BBL, and only weak turbulence in the inertial dissipation range and low bottom convective mixing are present. At the same time the well-mixed part of the BBL overlays the margin at $27-\mathrm{m}$ depth and no macroscopic oxygen gradient is present (Fig. 1). The constant oxygen profile and the low turbulence lead to the observed intermittency of turbulent oxygen transport. After the stagnation of the flow, the BBL moves downslope and the shear is again high enough to induce turbulent mixing against the density gradient of the BBL.

Until now, EC studies in aquatic systems have been mainly used to determine oxygen fluxes into or from the sediment. To relate our work with these previous studies it

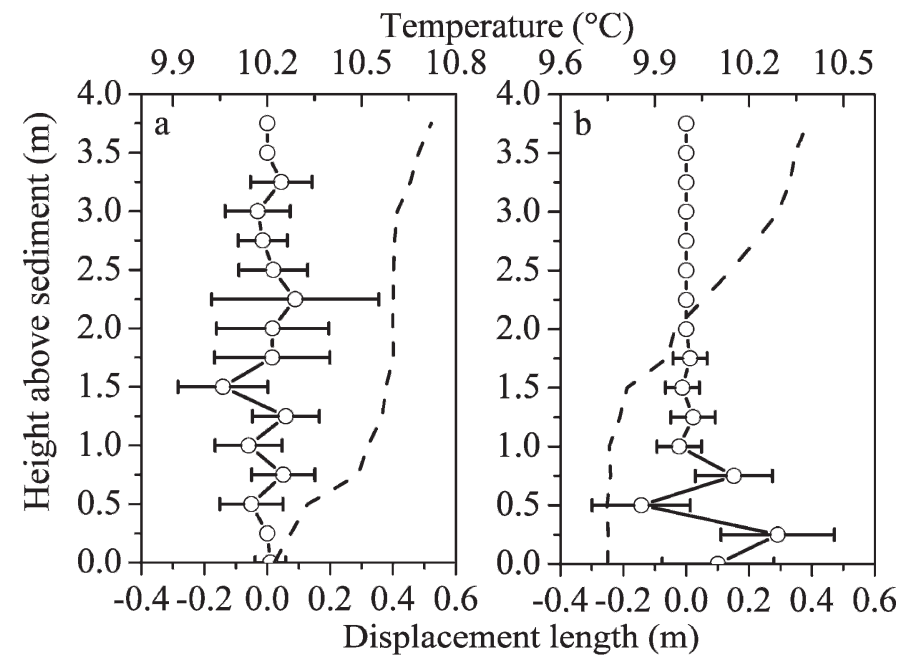

Fig. 9. One hour averages of displacement length (symbols) and temperature profiles (dashed line) at (a) $t=1 \mathrm{~h}$ (period with oxygen flux) and (b) $t=6 \mathrm{~h}$ (period without oxygen flux) determined from thermistor vertical array. Bars denote standard deviations.

is necessary to discuss the difference in the interpretation of previous EC studies and our work. The turbulent transport of oxygen in the water column can be described by the twodimensional transport equation for scalar quantities:

$$
\frac{\partial \bar{c}}{\partial t}+\bar{u} \frac{\partial \bar{c}}{\partial x}+\bar{w} \frac{\partial \bar{c}}{\partial z}=-\left[\frac{\partial J_{x}}{\partial x}+\frac{\partial J_{z}}{\partial z}\right]+S_{c}
$$

where $J_{x}$ and $J_{z}$ are horizontal and vertical fluxes, $S_{c}$ is the source-sink term of the oxygen concentration $c$, and $u, w$, and $c$ denote time-averaged quantities. $\partial \bar{c} / \partial t$ represents the change of the averaged concentration over time $t$, $\bar{u}(\partial \bar{c} / \partial x)+\bar{w}(\partial \bar{c} / \partial z)$ denotes the advective transport of the oxygen by mean flow, $-\left[\left(\partial J_{x} / \partial x\right)+\left(\partial J_{z} / \partial z\right)\right]$ represents the divergence of the flux in horizontal and vertical direction, and $S_{c}$ denotes the sink or source $S_{c}$ of oxygen in the water column.

In most EC studies, steady state and a nondivergent horizontal turbulent transport are assumed. $\bar{w}(\partial \bar{c} / \partial z)$ reduces to zero if there is no horizontal concentration gradient and the average vertical velocity is zero. Under all these assumptions, Eq. 6 reduces to

$$
\frac{\partial J_{z}}{\partial z}-S_{c}=0
$$

If we assume that $S_{c}$ in the water column is equal to 0 and neglect diffusion, we can directly use the vertical turbulent flux $\overline{w^{\prime} c^{\prime}}$ measured at a certain elevation to determine the flux into the sediment $J_{\text {sed }}$ :

$$
J_{\text {sed }}=\overline{w^{\prime} c^{\prime}}
$$

Eq. 8 was a reasonable assumption for studies conducted under highly turbulent, steady-state conditions (Berg et al. 2003; McGinnis et al. 2008). However, these conditions do not hold for systems like Lake Alpnach with dynamic and 


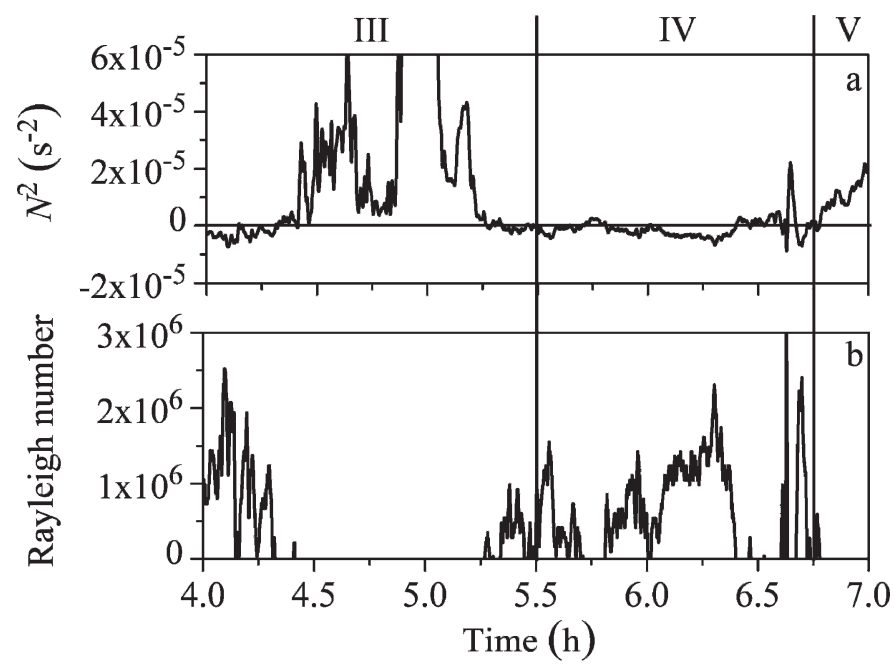

Fig. 10. (a) Stability, expressed as $N^{2}$, calculated from thermistors at $z=0, z=0.25$, and $z=0.5 \mathrm{~m}$ above sediment during flux free periods III and IV and beginning of period $V$ (Fig. 1b). (b) Rayleigh numbers for same periods calculated for a mixing length of $0.5 \mathrm{~m}$.

intermittent turbulence. The EC technique measures the turbulent flux of a solute through a horizontal plane, which cannot necessarily be interpreted as the sediment oxygen uptake (Fig. 2). Therefore we must interpret the short-term vertical fluxes more carefully in highly intermittent systems. Both the stagnant and actively sheared phases must be resolved to estimate oxygen budgets that reflect the sediment oxygen uptake.

In this study, measurements conducted over half a seiching period demonstrated both mixing phases. The averaged turbulent exchange of oxygen between the BBL and lake interior was $9.2 \mathrm{mmol} \mathrm{m}{ }^{2} \mathrm{~d}^{1}$, which was somewhat lower than the oxygen uptake of $13 \pm$ $2 \mathrm{mmol} \mathrm{m} 2 \mathrm{~d}^{1}$ determined from the oxygen profiles. The discrepancy between sediment oxygen uptake and turbulent oxygen transport also explains the observed oxygen depletion in the BBL of $\sim 25 \mathrm{mmol} \mathrm{m}{ }^{3}$ compared with the lake interior. A flood replaced most of the bottom water of Lake Alpnach and established a rather homogenous oxygen distribution $24 \mathrm{~d}$ before our study. This event allows us to estimate roughly the time that was necessary to establish the observed oxygen depletion in the BBL. If we assume a typical thickness of the BBL of $\sim 3 \mathrm{~m}$, we can calculate the oxygen deficit of the BBL roughly by $25 \mathrm{mmol} \mathrm{m}{ }^{3} \times 3 \mathrm{~m}=75 \mathrm{mmol} \mathrm{m}{ }^{2}$. Since the difference between the sediment oxygen flux and the turbulent oxygen flux in this study was $5 \mathrm{mmol} \mathrm{m} \mathrm{m}^{2}$, our calculation predicts that $15 \mathrm{~d}\left(75 \mathrm{mmol} \mathrm{m}{ }^{2} \times\left(5 \mathrm{mmol} \mathrm{m}^{2} \mathrm{~d}^{1}\right){ }^{1}\right)$ were necessary to establish the observed oxygen deficit. This is reasonable given that the flood occurred $24 \mathrm{~d}$ previously. The flux determined by the EC technique may also contain some systematic error, since we cannot be sure whether we have captured all properties of the seiching system such as the harmonics of the BBL oscillations with period lengths of 6 and $8 \mathrm{~h}$ (Münnich et al. 1992). Measurements over several seiche periods are necessary for representative flux estimates and more insight in the long-term variability of these fluxes.
Whereas the dynamics of internal mixing processes of the BBL (Wüest and Gloor 1998; Gloor et al. 2000) are becoming better understood, and the processes occurring at the sediment water interface have been closely investigated with respect to momentum (Caldwell and Chriss 1979; Brand et al. 2007) and solute exchange (Jørgensen and Boudreau 2001), little research has been undertaken to understand the solute transfer between the BBL and the interior of lakes. These transport processes are crucial for the solute exchange between the water column and the sediment of the lake. Moreover, slopes are important factors for the increased efficiency of the basinwide solute transport by the BBL in lakes as has been observed by Goudsmit et al. (1997). The EC technique has therefore proved to be an excellent tool for the study of turbulent oxygen exchange between the BBL and the lake interior.

\section{References}

Berg, P., N. Risgaard Petersen, and S. Rysgaard. 1998. Interpretation of measured concentration profiles in sediment pore water. Limnol. Oceanogr. 43: 15001510.

, H. Røy, F. Janssen, V. Meyer, B. B. Jørgensen, M. Huttel, And D. De Beer. 2003. Oxygen uptake by aquatic sediments measured with a novel non invasive eddy correla tion technique. Mar. Ecol. Prog. Ser. 261: 7583.

Boudreau, B. P., And B. B. Jørgensen. 2001. The benthic boundary layer. Oxford Univ. Press.

BRAND, A., AND OTHERS. 2007. Microsensor for in situ flow measurements in benthic boundary layers at sub millimeter resolution with extremely slow flow. Limnol. Oceanogr. Methods 5: 185191.

Caldwell, D. R., And T. M. Chriss. 1979. Viscous sublayer at the sea floor. Science 205: 11311132.

Desjardins, R. L., J. I. Macpherson, P. H. Schuepp, and F. KARANJA. 1989. An evaluation of aircraft flux measurements of $\mathrm{CO}_{2}$, water vapor and sensible heat. Boundary Layer Meteorol. 47: 5569.

Famulari, D., D. Fowler, K. Hargreaves, C. Milford, E. Nemitz, M. A. Sutton, and K. Weston. 2004. Measuring eddy covariance fluxes of ammonia using tunable diode laser absorption spectroscopy. Water Air Soil Pollut. 4: 151158.

Fox, R. W., A. T. McDonald, and P. J. Pritchard. 2004. Introduction to fluid mechanics. Wiley.

Gibson, C. H., And W. H. Schwarz. 1963. The universal equilibrium spectra of turbulent velocity and scalar fields. J. Fluid Mech. 16: 365384.

Gloor, M., A. Wuest, and D. M. Imboden. 2000. Dynamics of mixed bottom boundary layers and its implications for diapycnal transport in a stratified, natural water basin. J. Geophys. Res. Oceans 105: 86298646.

Goudsmit, G. H., F. Peeters, M. Gloor, and A. Wuest. 1997. Boundary versus internal diapycnal mixing in stratified natural waters. J. Geophys. Res. Oceans 102: 27903 27914

Jørgensen, B. B., And B. P. Boudreau. 2001. Diagenesis and sediment water exchange, p. 211 244. In B. P. Boudreau and B. B. Jørgensen [eds.], The benthic boundary layer. Oxford Univ. Press.

, AND D. J. D. Marais. 1990. The diffusive boundary layer of sediments: Oxygen microgradients over a microbial mat. Limnol. Oceanogr. 35: 13431355.

Kaimal, J. C., AND J. E. Gaynor. 1983. The boulder atmospheric observatory. J. Clim. Appl. Meteorol. 22: 863880. 
Kuwae, T., K. Kamio, T. Inoue, E. Miyoshi, and Y. Uchiyama. 2006. Oxygen exchange flux between sediment and water in an intertidal sandflat, measured in situ by the eddy correlation method. Mar. Ecol. Prog. Ser. 307: 5968.

Lee, X., W. Massmann, and B. Law. 2004. Handbook of micrometeorology a guide for surface flux measurement and analysis. Kluwer.

Lorke, A., B. Muller, M. Maerki, And A. Wuest. 2003. Breathing sediments: The control of diffusive transport across the sediment water interface by periodic boundary layer turbulence. Limnol. Oceanogr. 48: 20772085.

, F. Peeters, and A. Wuest. 2005. Shear induced convective mixing in bottom boundary layers on slopes. Limnol. Oceanogr. 50: 16121619.

, L. Umlauf, T. Jonas, and A. Wuest. 2002. Dynamics of turbulence in low speed oscillating bottom boundary layers of stratified basins. Environ. Fluid Mech. 2: 291313.

Maerki, M., B. Muller, and B. Wehrli. 2006. Microscale mineralization pathways in surface sediments: A chemical sensor study in Lake Baikal. Limnol. Oceanogr. 51: 13421354.

McGinnis, D. F., P. Berg, A. Brand, C. Lorrai, T. J. Edmonds, AND A. Wuest. 2008. Measurements of eddy correlation oxygen fluxes in shallow freshwaters: Towards routine applications and analysis. Geophys. Res. Lett. 35: L04403, doi: 10.1029/2007GL032747.

Muller, B., M. Marki, C. Dinkel, R. Stierli, and B. Wehrli. 2002. In situ measurements in lake sediments using ion selective electrodes with a profiling lander system, p. 126143 In M. Taillefert and T. F. Rozan [eds.], Environmental electrochemistry Analyses of trace element biogeochemistry. American Chemical Society.
Munnich, M., A. Wuest, And D. M. Imboden. 1992. Observations of the second vertical mode of the internal seiche in an alpine lake. Limnol. Oceanogr. 37: 17051719.

Oncley, S. P., C. A. Friehe, J. C. Larue, J. A. Businger, E. C. Itsweire, And S. S. Chang. 1996. Surface layer fluxes, profiles, and turbulence measurements over uniform ter rain under near neutral conditions. J. Atmos. Sci. 53: 10291044

Stillinger, D. C., K. N. Helland, and C. W. Van Atta. 1983. Experiments on the transition of homogeneous turbulence to internal waves in a stratified fluid. J. Fluid Mech. 131: 91122

Stull, R. B. 1988. An introduction to boundary layer meteorol ogy. Kluwer.

Turner, J. S. 1973. Buoyancy effects in fluids. Cambridge Univ. Press.

Welch, P. D. 1967. The use of fast Fourier transform for the estimation of power spectra: A method based on time averaging over short, modified Periodograms. IEEE Trans. Audio Electroacoust. 15: 7073.

Wuest, A., And M. Gloor. 1998. Bottom boundary mixing: The role of near sediment density stratification, p. 485 502. In J. Imberger [ed.], Physical processes in lakes and oceans. Coastal and estuarine studies. AGU.

, AND A. LoRke. 2003. Small scale hydrodynamics in lakes. Ann. Rev. Fluid Mech. 35: 373412.

Received: 12 July 2007

Amended: 3 April 2008

Accepted: 7 April 2008 